\title{
Production and import of energy - Poland against EU countries
}

\author{
Sylwia Lorenc ${ }^{1}$ and Marcin Migza ${ }^{1, a}$ \\ ${ }^{1}$ AGH University of Science and Technology, Department of Economy and Management in Industry, al. Mickiewicza 30, 30-059 Krakow, \\ Poland
}

\begin{abstract}
The purpose of this paper is to present the Polish energy market compared to the countries of the 'old' (UE15 ) and the 'new' (UE-28) European Union. Today, the EU consists of 28 states of different size, population, economy, and energy structure. Without presenting the political-economic context, a comparison between energy market in Poland to those in the other $28 \mathrm{EU}$ countries would not produce a reliable picture. The existence of these discrepancies was a motivating factor in the authors' efforts to account for the Polish energy market as compared to the 'old' and 'new' EU states. The data were presented and analysed according to the different kinds of energy sources.
\end{abstract}

\section{Introduction}

Changes occurring in the European economy require application of pioneering solutions in the energy policy scope. This necessity caused by unfavorable effects occurring last years in the world economy including a growing environment pollution, energy power failures and an abrupt decrease of the power industry raw materials prices.

Poland as a member country of the European Union is actively participating in creating the common energy policy, but due to unfavorable tendencies occurring in the sector and the necessity of fulfilling the ecological obligations is facing a significant challenge. From one side there is a growing demand for energy and strong dependence on external supplies of natural gas and crude oil, while from the second side there are obligations concerning the environment protection within the energy packet ,3×20" [1]. Within the strategy „Europe 2020" assumptions of the European Commission oblige Poland to reduce greenhouse gases emission by $20 \%$ to the year 2020 (as compared with the year 1990), to increase the energy efficiency by $20 \%$ and to increase the fraction of renewable energy sources by $20 \%$ in the general energy production. The climatic policy of the EU caused that the Polish coal-based economy increased fractions of alternative and low-emission energy sources [1].

Pursuing a uniform energy policy, at the present configuration of the Union, without in-depth market analysis in individual countries, seems impossible. High diversification of the European energy markets causes that the detailed specification of the energy situation in each member country is necessary. The energy sector structure in the member countries is determined by the EU directives, which demand the energy markets liberalization. The aim of such policy is striving

\footnotetext{
a Corresponding author: migza@agh.edu.pl
}

to the energy safety improvement, decrease of prices and facilitation of international cooperation by means of forming the competitive electric energy market. These elements should finally contribute to the reduction of the environment pollution. On account of this, alternative and low-emission energy sources started to play the key role in the energy policy of the EU.

One of the most important threats influencing the energy policy of the Union is a high dependence of the European Union on external supplies of energy carriers. In the year $2014,53.4 \%$ of gross inland energy consumption in the EU was imported [2]. This value stabilized in last years in the whole EU and in Poland even slightly decreased, which is shown in Table 1 . However, it should be remembered, that the growing rate of the Polish import of energy carriers during last 18 years was much higher, which is presented in Figure 1.

Table 1. Energy dependence of EU in 2010-2014 [2].

\begin{tabular}{|c|c|c|c|c|c|}
\hline & $\mathbf{2 0 1 0}$ & $\mathbf{2 0 1 1}$ & $\mathbf{2 0 1 2}$ & $\mathbf{2 0 1 3}$ & $\mathbf{2 0 1 4}$ \\
\hline EU-28 & $52,6 \%$ & $54,0 \%$ & $53,3 \%$ & $53,1 \%$ & $53,4 \%$ \\
\hline Poland & $31,3 \%$ & $33,4 \%$ & $30,6 \%$ & $25,6 \%$ & $28,6 \%$ \\
\hline
\end{tabular}

In order to decrease the EU energy dependence, it is necessary to conduct the energy policy not only directed towards limitations of consumption, but first of all promoting the energy production in the EU countries.

The current social-economic situation inside the Community is not uniform. The present day Union consists of 28 countries of various sizes, populations, power industry structures and economic conditions. Significant differences in economic potentials, between the 'old' and 'new' European Union countries, can be still observed, including the energy sector. 


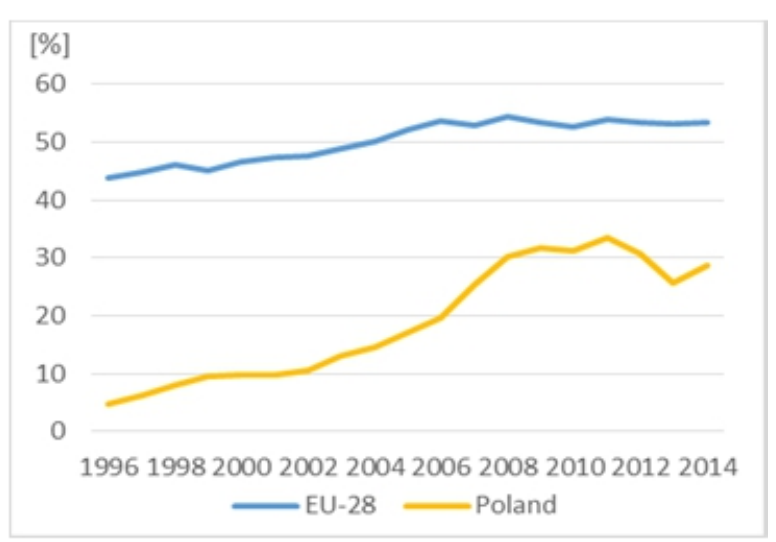

Figure 1. Energy dependence of EU in 1996-2014 [2].

\section{Main dividing axle of the EU - accession date}

The efficiently operating energy production sector is one of the key factors of increasing the economic potential of developing countries as well as of highly developed countries of a significant industrialization degree.

One of the most important measures of the economic growth is the Gross Domestic Product (GDP) per capita. Values of this index for individual EU countries calculated on the basis of Eurostat data are presented in Table 2.

Table 2. GDP per capita in EU 2010-2014 [3,4].

\begin{tabular}{|c|c|c|c|c|c|}
\hline & $\mathbf{2 0 1 0}$ & $\mathbf{2 0 1 1}$ & $\mathbf{2 0 1 2}$ & $\mathbf{2 0 1 3}$ & $\mathbf{2 0 1 4}$ \\
\hline EU-28 & 25394 & 26096 & 26618 & 26694 & 27486 \\
\hline EU-15 & 29582 & 30315 & 30935 & 31051 & 31842 \\
\hline EU-N13 & 9612 & 10103 & 10231 & 10426 & 10729 \\
\hline Poland & 9509 & 9988 & 10227 & 10373 & 10808 \\
\hline
\end{tabular}

The values of the GDP per capita index indicates that countries of the so called 'new Union' (ten countries which entered the Union in the year 2004 : Cyprus, Czech Republic, Hungary, Latvia, Lithuania, Estonia, Malta, Poland, Slovenia, Slovakia, two in 2007: Bulgaria, Rumania and Croatia in 2013) still do not have the economic potential allowing to compete with economics of the 'oldUnion' (fifteen countries which created the Union or entered into it before the year 2000 : Austria, Belgium, Dania, Finland, France, Greece, Spain, Holland, Ireland, Luxemburg, Germany, Portugal, Sweden, Great Britain and Italy). The GDP per capita in Poland nearly ideally reflects the average value of this index for the EU-N13 countries. This dependence is presented in Figure 2.

The Pearson correlation coefficient between values of the index in Poland and the average for 13 'new' EU countries, calculated for years 2007-2014 equals more than 0.988, while the correlation level between Poland and the average of the whole Union equals only 0.837 . This shows that countries of the 'new' Union are a good comparing background for Poland for further analyses in the energy production sector.

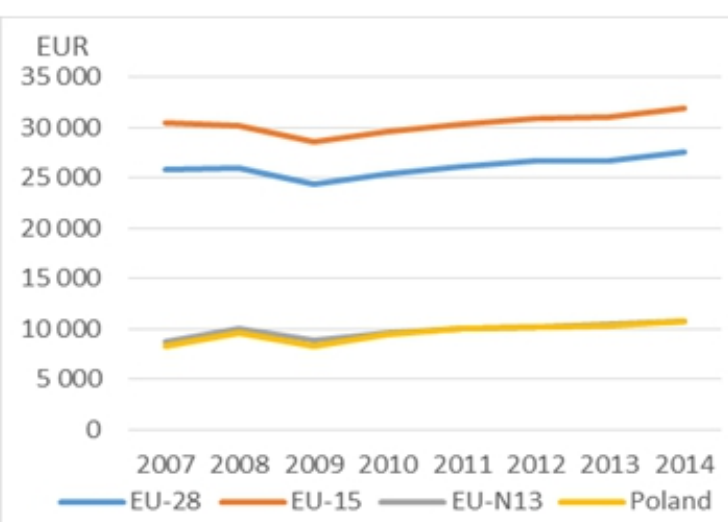

Figure 2. GDP per capita in EU, in 2007-2014 [3,4].

\section{Energy production in the European Union}

The main problem with which the EU is wrestling, is warranting the energy supply safety. One of the reasons of the high dependence on the import is a decrease of the energy production in the EU. The data are presented in Table 3.

Table 3. Primary production of energy (1 000 tonnes of oil equivalent) [5].

\begin{tabular}{|l|l|l|l|l|l|}
\hline & $\mathbf{2 0 1 0}$ & $\mathbf{2 0 1 1}$ & $\mathbf{2 0 1 2}$ & $\mathbf{2 0 1 3}$ & $\mathbf{2 0 1 4}$ \\
\hline EU-28 & 835704 & 802122 & 795148 & 790398 & 771682 \\
\hline EU-15 & 665026 & 628534 & 619796 & 619362 & 603734 \\
\hline EU-N13 & 170678 & 173589 & 175351 & 171036 & 167948 \\
\hline Poland & 66740 & 67681 & 70971 & 70571 & 66867 \\
\hline
\end{tabular}

In the year 2014 the total production of the primary energy from all sources in the UE-28 equaled less than 772 million tonnes of the oil equivalent. This constitutes the continuation of the European decreasing tendency, which could be observed during last years. Among the 'new' thirteen countries this tendency is significantly weaker. Poland does not share these decreasing tendencies and in the energy production per capita is significantly above the average of EU-28, EU-15 and EU-N13 (Table 4 and Figure 3).

Table 4. Primary production of energy per capita in EU (tonnes of oil equivalent) [4,5].

\begin{tabular}{|l|l|l|l|l|l|}
\hline & $\mathbf{2 0 1 0}$ & $\mathbf{2 0 1 1}$ & $\mathbf{2 0 1 2}$ & $\mathbf{2 0 1 3}$ & $\mathbf{2 0 1 4}$ \\
\hline EU-28 & 1,6588 & 1,5882 & 1,5758 & 1,5573 & 1,5196 \\
\hline EU-15 & 1,6703 & 1,5729 & 1,5518 & 1,5443 & 1,498 \\
\hline EU-N13 & 1,6153 & 1,6463 & 1,6665 & 1,6289 & 1,603 \\
\hline Poland & 1,7543 & 1,7781 & 1,8646 & 1,8552 & 1,7591 \\
\hline
\end{tabular}




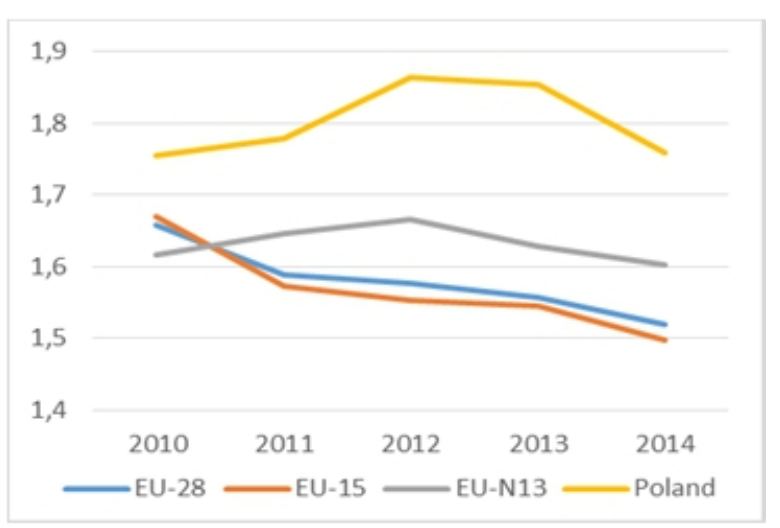

Figure 3. Primary production of energy per capita in EU (tonnes of oil equivalent) $[4,5]$.

The fact that the Energy sector is also subjected to the division into the 'old' and 'new' Union is the best seen on the example of the energy production method. The participation of individual energy carriers in the general energy production in the EU in 2014, is shown in Table 5 .

Table 5. Share of different energy sources in energy production in the EU [5].

\begin{tabular}{|c|c|c|c|c|}
\hline & \multicolumn{4}{|c|}{2014} \\
\hline Energy source & EU-28 & EU-15 & EU-N13 & Poland \\
\hline Nucle ar he at & $29,3 \%$ & $33,4 \%$ & $14,7 \%$ & $0,0 \%$ \\
\hline Renewable & $25,4 \%$ & $27,2 \%$ & $18,8 \%$ & $12,0 \%$ \\
\hline Natural gas & $15,3 \%$ & $16,9 \%$ & $9,4 \%$ & $5,6 \%$ \\
\hline Crude oil + NGL & $8,8 \%$ & $10,1 \%$ & $4,0 \%$ & $1,4 \%$ \\
\hline Solid fuels & $19,4 \%$ & $10,2 \%$ & $52,2 \%$ & $80,2 \%$ \\
\hline Others & $1,9 \%$ & $2,2 \%$ & $0,8 \%$ & $0,8 \%$ \\
\hline SUM & $100,0 \%$ & $100,0 \%$ & $100,0 \%$ & $100,0 \%$ \\
\hline
\end{tabular}

A high participation of energy obtained from solid fuels is characteristic for the 'new' Union countries. In this respect Poland with a participation above $80 \%$ stands out even at the EU-N13 background.

In order to characterize better the individual energy carriers and to show actual trends, the main groups of energy sources are characterized separately.

\subsection{Nuclear heat}

The primary energy produced in EU-28 in the year 2014 originated from various sources, out of which the highest fraction constituted the nuclear energy $(29.3 \%$ of the total production). Nuclear fuel was of a especially high meaning in the 'old' Union countries (33.4\%). In years 2012-2014 an insignificant decrease of the atomic power industry in EU-28 countries could be observed. Poland is one of 14 member countries, which do not use the atomic energy. In consideration of a negative reception of the nuclear energy all attempts of building nuclear blocks were ended with a fiasco.
Table 6. Primary production of energy from nuclear (1 000 tonnes of oil equivalent) [5].

\begin{tabular}{|c|c|c|c|c|c|}
\hline & $\mathbf{2 0 1 0}$ & $\mathbf{2 0 1 1}$ & $\mathbf{2 0 1 2}$ & $\mathbf{2 0 1 3}$ & $\mathbf{2 0 1 4}$ \\
\hline EU-28 & 236563 & 234007 & 227719 & 226285 & 226132 \\
\hline EU-15 & 213004 & 209739 & 203261 & 202211 & 201438 \\
\hline EU-N13 & 23558 & 24268 & 24458 & 24074 & 24694 \\
\hline Poland & 0 & 0 & 0 & 0 & 0 \\
\hline
\end{tabular}

Table 7. Share of nuclear energy in energy production in EU [5].

\begin{tabular}{|c|c|c|c|c|c|}
\hline & $\mathbf{2 0 1 0}$ & $\mathbf{2 0 1 1}$ & $\mathbf{2 0 1 2}$ & $\mathbf{2 0 1 3}$ & $\mathbf{2 0 1 4}$ \\
\hline EU-28 & $28,3 \%$ & $29,2 \%$ & $28,6 \%$ & $28,6 \%$ & $29,3 \%$ \\
\hline EU-15 & $32,0 \%$ & $33,4 \%$ & $32,8 \%$ & $32,6 \%$ & $33,4 \%$ \\
\hline EU-N13 & $13,8 \%$ & $14,0 \%$ & $13,9 \%$ & $14,1 \%$ & $14,7 \%$ \\
\hline Poland & $0,0 \%$ & $0,0 \%$ & $0,0 \%$ & $0,0 \%$ & $0,0 \%$ \\
\hline
\end{tabular}

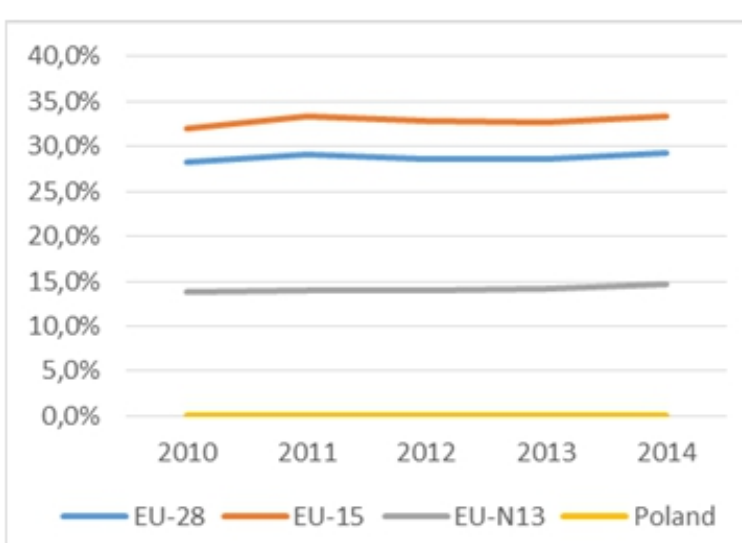

Figure 4. Share of nuclear energy in energy production in EU [5].

The main factor influencing weakening of the public interest in obtaining energy from nuclear power plants are potential effects of nuclear failures. Each member country can independently decide whether it wants to develop nuclear energy plants. The European Commission remains officially neutral with regard to the nuclear energy development. In October 2007 the European Parliament promoted the nuclear heat and power plants development as a necessary option for the European Union, emphasizing that each country has the right to decide on the nuclear energy introduction, but the effects of its decision will influence electric energy prices in the whole Union [6].

Table 8. Primary production of energy from renewable in EU (1 000 tonnes of oil equivalent) [5].

\begin{tabular}{|c|c|c|c|c|c|}
\hline & $\mathbf{2 0 1 0}$ & $\mathbf{2 0 1 1}$ & $\mathbf{2 0 1 2}$ & $\mathbf{2 0 1 3}$ & $\mathbf{2 0 1 4}$ \\
\hline EU-28 & 167890 & 164267 & 180577 & 192838 & 195846 \\
\hline EU-15 & 140119 & 136885 & 150916 & 161682 & 164204 \\
\hline EU-N13 & 27771 & 27381 & 29660 & 31156 & 31642 \\
\hline Poland & 6845,5 & 7439,4 & 8465,6 & 8511,5 & 8054,4 \\
\hline
\end{tabular}


In order to realize the strategic purpose of the energy related EU policy, it means the diversification of energy sources, the development of the production technology of rational costs, especially nuclear energy with zero emission of gases and dusts harmful for the environment and with a low sensibility to increased uranium prices, is necessary [1].

From the point of view of the Polish natural resources, utilization of the nuclear energy is not necessary. Current fundamental oppositions of the social party cause that the vision of the nuclear power plants development in the nearest years is not much real.

\subsection{Renewable}

Due to the necessity of implementing the new, energy related policy an increased meaning of renewable energy sources has been observed (Table 8). One fourth of the total production of the primary energy in UE- 28 originates from this source $(25.4 \%)$ (Table 9 ). An increase of the primary energy from the renewable sources was

Table 9. Share of renewable energy in energy production in EU

\begin{tabular}{|c|c|c|c|c|c|}
\hline & $\mathbf{2 0 1 0}$ & $\mathbf{2 0 1 1}$ & $\mathbf{2 0 1 2}$ & $\mathbf{2 0 1 3}$ & $\mathbf{2 0 1 4}$ \\
\hline EU-28 & $20,1 \%$ & $20,5 \%$ & $22,7 \%$ & $24,4 \%$ & $25,4 \%$ \\
\hline EU-15 & $21,1 \%$ & $21,8 \%$ & $24,3 \%$ & $26,1 \%$ & $27,2 \%$ \\
\hline EU-N13 & $16,3 \%$ & $15,8 \%$ & $16,9 \%$ & $18,2 \%$ & $18,8 \%$ \\
\hline Poland & $10,3 \%$ & $11,0 \%$ & $11,9 \%$ & $12,1 \%$ & $12,0 \%$ \\
\hline
\end{tabular}

higher than in case of all other energy kinds, and stayed at the similar level for the largest part of the period: 2010 to 2014. Poland, at the background of the remaining EU countries, is still behind. Only $12 \%$ of the total energy production originates from alternative sources. A stable increase of the meaning of the renewable energy sources in individual member countries instills optimism. This dependence is presented in Figure 5.

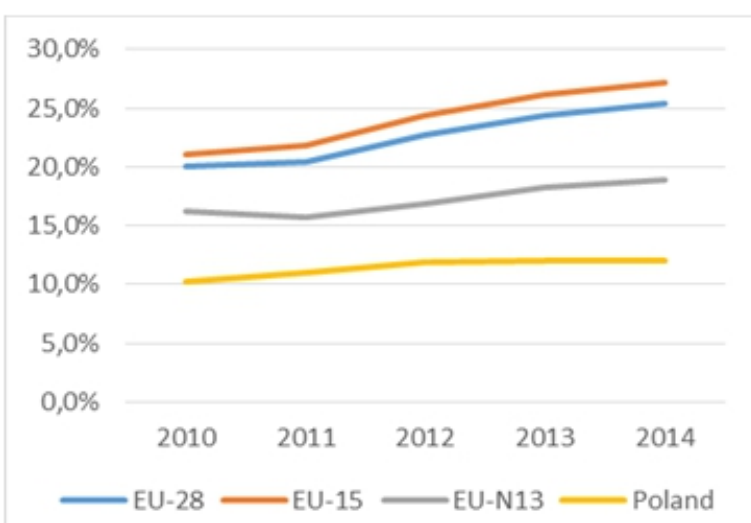

Figure 5. Share of renewable energy in energy production in $\mathrm{EU}[5]$.

The European Union is the leader in the range of the renewable sources technologies, into which the wind, solar, hydroelectric, oceanic, geothermal, biomass and bio-fuels energy can be numbered, constitute the alternative for fossil fuels [7]. The increase of utilizing
Table 10. Primary production of energy from natural gas (1 000 tonnes of oil equivalent) [5].

\begin{tabular}{|c|c|c|c|c|c|}
\hline & $\mathbf{2 0 1 0}$ & $\mathbf{2 0 1 1}$ & $\mathbf{2 0 1 2}$ & $\mathbf{2 0 1 3}$ & $\mathbf{2 0 1 4}$ \\
\hline EU-28 & 159676 & 141619 & 133054 & 131823 & 117986 \\
\hline EU-15 & 142560 & 124335 & 116410 & 115801 & 102155 \\
\hline EU-N13 & 17116 & 17284 & 16644 & 16022 & 15831 \\
\hline Poland & 3693 & 3849,8 & 3906,8 & 3823,1 & 3726,3 \\
\hline
\end{tabular}

these sources ensures the local energy supply safety, decreases the dependence on uncertain conditions in the fossil fuels markets and influences a reduction of contaminations emitted to the environment. Poland has an access to large and various resources of renewable energy sources. However, there are infrastructural limitations, which significantly hamper utilizing this potential [1].

\subsection{Natural gas}

The production level of the primary energy of natural gas was decreased by app. 8\% among EU-28 and EU-15 countries, in the period: 2010-2014. The smallest fluctuations occurred in the 'new' Union countries, including Poland (Table 8 and Table 9). The natural gas fraction in the total energy production is maintained at the stable level oscillating round 5\%. This dependence is presented in Table 10, Table 11 and Figure 6.

Table 11. Share of natural gas in energy production in EU [5].

\begin{tabular}{|l|c|c|c|c|c|}
\hline & $\mathbf{2 0 1 0}$ & $\mathbf{2 0 1 1}$ & $\mathbf{2 0 1 2}$ & $\mathbf{2 0 1 3}$ & $\mathbf{2 0 1 4}$ \\
\hline EU-28 & $19,1 \%$ & $17,7 \%$ & $16,7 \%$ & $16,7 \%$ & $15,3 \%$ \\
\hline EU-15 & $21,4 \%$ & $19,8 \%$ & $18,8 \%$ & $18,7 \%$ & $16,9 \%$ \\
\hline EU-N13 & $10,0 \%$ & $10,0 \%$ & $9,5 \%$ & $9,4 \%$ & $9,4 \%$ \\
\hline Poland & $5,5 \%$ & $5,7 \%$ & $5,5 \%$ & $5,4 \%$ & $5,6 \%$ \\
\hline
\end{tabular}

The energy production of natural gas constitutes $1 / 6$ of the total production in the EU-28 countries, $1 / 11$ in the 'new' Union, while only $1 / 20$ in Poland.

The energy production of natural gas is less harmful for the environment than other energy sources: the $\mathrm{CO}_{2}$ emission from gas burning is up to $30 \%$ lower than in case of crude oil and up to $60 \%$ lower than in case of coal. Emissions of other chemical substances such as mercury, sulphur and nitrogen dioxide are also significantly reduced [8].

The power industry safety of the EU in case of natural gas is threatened by shrinking resources of this raw material in the world and by strong dependence on the import, which probably is the cause of the decrease of the natural gas consumption in Europe.

The Polish natural gas market has a high potential. The energy policy within this space is based on the diversification of gas supply sources, which positively influences the energy safety in Poland. The creation of technological and physical possibilities of the natural gas import from the western direction indicates favorable perspectives for this energy sector. 


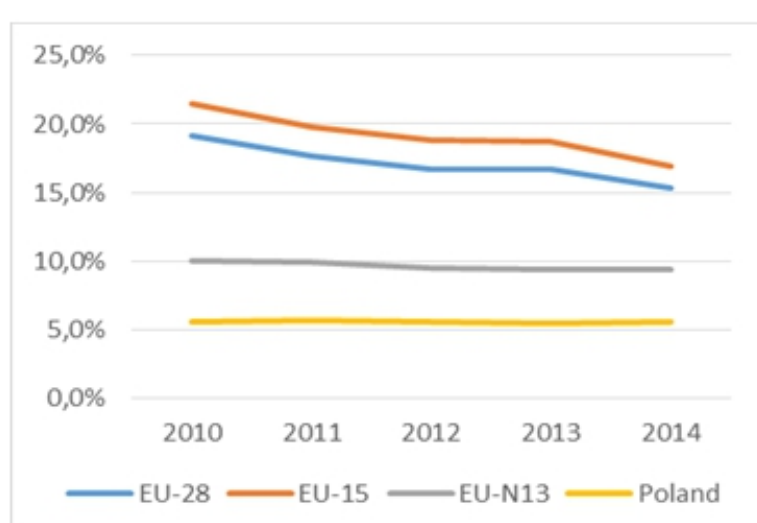

Figure 6. Share of natural gas in energy production in EU [5].

\subsection{Crude oil - NGL}

The energy production of crude oil and natural liquid gas decreases year by year (Figure 7); the highest declines occurred in EU-28 and EU-15 countries (Table 12). The gas and crude oil utilization in the 'new' Union countries and in Poland is at the stabilized level: 'new' Union (app. $4 \%$ ), Poland (app. 1\%) of the total primary energy production (Table 13).

Table 12. Primary production of energy from crude oil and NGL (1 000 tonnes of oil equivalent) [5].

\begin{tabular}{|c|c|c|c|c|c|}
\hline & $\mathbf{2 0 1 0}$ & $\mathbf{2 0 1 1}$ & $\mathbf{2 0 1 2}$ & $\mathbf{2 0 1 3}$ & $\mathbf{2 0 1 4}$ \\
\hline EU-28 & 94162 & 81966 & 74007 & 69595 & 68004 \\
\hline EU-15 & 86867 & 74978 & 67422 & 62680 & 61231 \\
\hline EU-N13 & 7294,5 & 6988,4 & 6584,4 & 6915,5 & 6773,3 \\
\hline Poland & 681 & 603,4 & 663,7 & 949,2 & 932,2 \\
\hline
\end{tabular}

The dependence of the EU on the energy import, especially crude oil and - in the last period - also natural gas is the reason of anxieties related to the supplies safety. In a similar fashion as in case of natural gas the drop in utilisation of crude oil and natural liquid gas is probably caused by the realisation of the energy related, Union policy. A small fraction of these energy sources in the Polish energy balance causes that there is not a direct threat of losing the energy stability. However, on the other side, even small supplies cause threatening of the monopolistic price policy of the suppliers. In order to minimize the risk, similarly as in the natural gas case, it is necessary to look for various directions of supplies and building storage accommodations for liquid fuels to ensure the supply continuity in an eventual crisis situation.

Table 13. Share of crude oil and NGL in energy production in $\mathrm{EU}[5]$.

\begin{tabular}{|c|c|c|c|c|c|}
\hline & $\mathbf{2 0 1 0}$ & $\mathbf{2 0 1 1}$ & $\mathbf{2 0 1 2}$ & $\mathbf{2 0 1 3}$ & $\mathbf{2 0 1 4}$ \\
\hline EU-28 & $11,3 \%$ & $10,2 \%$ & $9,3 \%$ & $8,8 \%$ & $8,8 \%$ \\
\hline EU-15 & $13,1 \%$ & $11,9 \%$ & $10,9 \%$ & $10,1 \%$ & $10,1 \%$ \\
\hline EU-N13 & $4,3 \%$ & $4,0 \%$ & $3,8 \%$ & $4,0 \%$ & $4,0 \%$ \\
\hline Poland & $1,0 \%$ & $0,9 \%$ & $0,9 \%$ & $1,3 \%$ & $1,4 \%$ \\
\hline
\end{tabular}

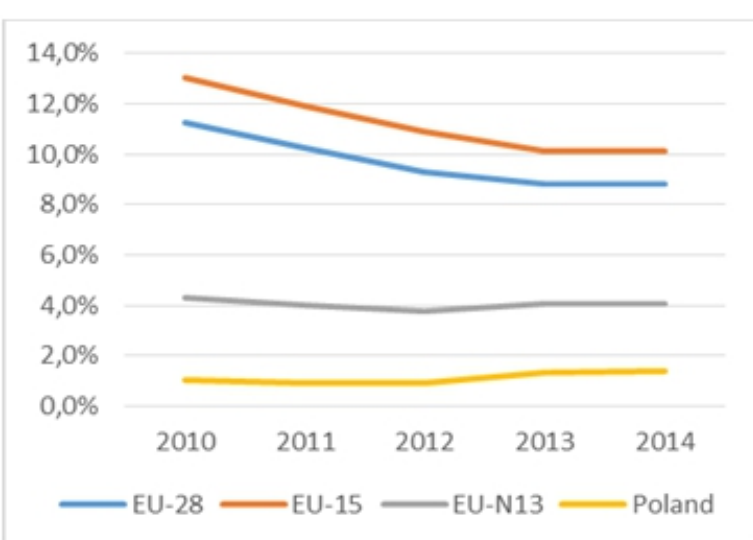

Figure 7. Share of crude oil and NGL in energy production in EU [5].

\subsection{Solid fuels}

According to the Eurostat data the fraction of solid fuels (hard coal, brown coal) decreases year by year (Table 14). In the year 2014 only $19,4 \%$ of energy consumed in EU28 originated from solid fuels (Table 15). A declining trend can be seen also in the EU-15 and 'new' Union countries. Hard coal is first of all localized in Poland (the largest resources), Czech and to a lower degree in Spain, Hungary, Great Britain and Germany. The brown coal resources spread from Germany to Greece. Solid fuels constitute the largest fraction in the energy production in Poland, in the year 2014 they equaled above $80 \%$. Poland, as the country having one of the largest hard coal resources, is able to be independent of the external supplies of solid fuels. Fractions of solid carriers in the total obtaining the primary energy in individual comparative groups is highly diversified (Figure 8). The EU recommendations oblige to the realization of the low-coal policy, especially to reduce the greenhouse gases and to increase the renewable energy sources utilization. During the last years the influence of these directives and the climatic package ' $3 \times 20$ ' on the participation of solid fuels in the total energy production, can be seen.

Fractions of solid carriers in the total obtaining the primary energy in individual comparative groups is highly diversified (Figure 8). The EU recommendations oblige to the realization of the low-coal policy, especially to reduce the greenhouse gases and to increase the renewable energy sources utilization. During the last years the influence of these directives and the climatic package ' $3 \times 20$ ' on the participation of solid fuels in the total energy production, can be seen.

Table 14. Primary production of energy from solid fuels (1 000 tonnes of oil equivalent) [5].

\begin{tabular}{|c|c|c|c|c|c|}
\hline & $\mathbf{2 0 1 0}$ & $\mathbf{2 0 1 1}$ & $\mathbf{2 0 1 2}$ & $\mathbf{2 0 1 3}$ & $\mathbf{2 0 1 4}$ \\
\hline EU-28 & 164005 & 166608 & 166056 & 155826 & 149335 \\
\hline EU-15 & 70011 & 70024 & 69132 & 64156 & 61701 \\
\hline EU-N13 & 93994 & 96584 & 96924 & 91670 & 87634 \\
\hline Poland & 55077 & 55298 & 57507 & 56835 & 53639 \\
\hline
\end{tabular}


For Poland as the country, having at its disposal significant hard coal resources the low-coal economy is unacceptable. Economic, social and environmental advantages determined by the sustainable development are possible without the necessity of resigning from the only one perspective and competitive energy source. The Tables of natural solid fuels resources in Poland indicate that Poland is totally independent of external supplies [9].The main fuel raw material in Poland is hard coal. Despite the self-sufficiency, Poland imports significant amounts of this raw material. This results from lower coal prices in other markets and better qualitative parameters of imported coal. The solution of this problem seems to be building new, more efficient power units, implementing modern processing technologies and restructuring of mines, all these at costs decreasing and joining the mining with the power industry.

On account of the fact that solid fuels still constitute an important element of the energy balance of the EU, the European Commission calls for introducing ecological technologies of the coal burning. The application and development of these technologies becomes the real perspective. Necessary financial investments in their development can result in the future in the breakthrough of the conventional energy production.

Table 15. Share of solid fuels in energy production in EU [5].

\begin{tabular}{|c|c|c|c|c|c|}
\hline & $\mathbf{2 0 1 0}$ & $\mathbf{2 0 1 1}$ & $\mathbf{2 0 1 2}$ & $\mathbf{2 0 1 3}$ & $\mathbf{2 0 1 4}$ \\
\hline EU-28 & $19,6 \%$ & $20,8 \%$ & $20,9 \%$ & $19,7 \%$ & $19,4 \%$ \\
\hline EU-15 & $10,5 \%$ & $11,1 \%$ & $11,2 \%$ & $10,4 \%$ & $10,2 \%$ \\
\hline EU-N13 & $55,1 \%$ & $55,6 \%$ & $55,3 \%$ & $53,6 \%$ & $52,2 \%$ \\
\hline Poland & $82,5 \%$ & $81,7 \%$ & $81,0 \%$ & $80,5 \%$ & $80,2 \%$ \\
\hline
\end{tabular}

\section{Conclusions}

A dynamic development of the European economy causes that the demand for the electric energy increases day by day. To satisfy the increasing demand for the electric current the diversification of the primary energy carriers and directions of their supplies is necessary (the so-called Energy Power Mix).

Decreasing production of the primary energy with using hard coal, brown coal, crude oil, natural gas and in the last period also the nuclear energy causes the situation in which meeting the EU demands is dependent in more than $50 \%$ on the primary energy import.

There are still considerable differences between countries of 'old' and 'new' EU regarding economic capabilities, which can also be observed in the energy sector.

Polish energy sector should be compared not only to the EU average, but above all with countries that have similar history and potential. However, even against countries of the 'new' EU Poland is still too much reliance on solid fuels (coal), and in far too little on renewable sources. Moreover, Poland should reduce the speed of growth of energy dependence, not imitating the old EU countries in this aspect.
Next to the problem of growing imports, the attention should be drawn to other aspects of creating the energy policy. There is a pressure of the EU to implement innovatory technologies in order to limit environmental hazards connected with coal, crude oil and natural gas. But there are also threats of applying pure technologies e.g. nuclear. These aspects cause that managing uniform energy policy in all European Union countries is quite a challenge.

The improvement of the energy efficiency and limitation of growing needs for fuels and energy, at maintaining the sustainable development regulations can become the recipe for the energy safety increase.

The energy crisis is for the Union a real threat and therefore it should develop more loyal mechanisms based on harmonizing interests of all member countries. The main task - in front of the European Union - is the development of common and efficient mechanisms of the energy policy, which will help member countries to manage with an eventual crisis related to energy supplies.

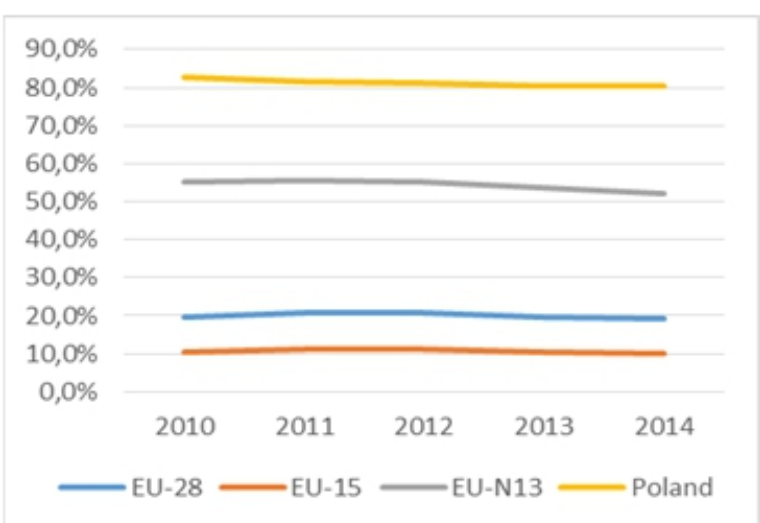

Figure 8. Share of solid fuels in energy production in EU [5].

\section{References}

1. http://www.cecgr.com/EnergyPolicy.pdf

2. http://ec.europa.eu/EnergyDependence

3.http://ec.europa.eu/eurostat/database

4. http://ec.europa.eu/eurostat/Demography

5. http://ec.europa.eu/eurostat/EnergyProduction

6. http://www.europarl.europa.eu/ConvEnergy

7. www.europarl.europa.eu

8. http://www.europagazniekonwencjonalny.pl/

9. http://ppg.ibngr.pl/ 